\title{
Prolactin-Producing Pituitary Gland
}

\section{Carcinoma}

National Cancer Institute

\section{Source}

National Cancer Institute. Prolactin-Producing Pituitary Gland Carcinoma. NCI Thesaurus. Code C5962.

A rare, hormonally functioning or non-functioning pituitary gland adenocarcinoma that produces prolactin. 